\title{
FATORES ASSOCIADOS À SOCIALIZAÇÃO PROFISSIONAL DE PROFESSORES UNIVERSITÁRIOS INICIANTES EM UMA INSTITUIÇÃO FEDERAL DE ENSINO
}

\author{
ASSOCIATED FACTORS: THE PROFESSIONAL SOCIALIZATION PROCESS OF \\ BEGINNER PROFESSORS IN A FEDERAL PUBLIC UNIVERSITY
}

\author{
SOCIALIZAÇÃO PROFISSIONAL DE PROFESSORES UNIVERSITÁRIOS \\ INICIANTES
}

THE PROFESSIONAL SOCIALIZATION PROCESS OF BEGINNER PROFESSORS

\author{
BONADIMAN, Heron Laiber ${ }^{1}$ \\ ROMAGNOLI, Roberta Carvalho ${ }^{2}$
}

\begin{abstract}
Resumo
No contexto da expansão do ensino público federal ocorrido na década de 2010, o objetivo do artigo foi analisar os fatores associados ao processo de socialização profissional de professores universitários iniciantes numa instituição de ensino superior pública federal do interior do estado de Minas Gerais, Brasil. Foram produzidos dados em cinco faculdades e institutos, onde foram entrevistados dez professores iniciantes e dois professores experientes e foram realizadas observações de campo entre os anos de 2014 e 2015. A partir dos dados foram construídos analisadores do processo de socialização profissional que revelaram os seguintes fatores associados à socialização profissional: a entrada no estabelecimento universitário desde a posse no serviço público, a mudança de localidade e de modo de vida, a relação dos professores iniciantes com a família e a transição de estudante de doutorado para professor do magistério superior. Concluiu-se que o processo de socialização profissional de professores iniciantes é um momento de embate entre forças instituintes e instituídas no estabelecimento universitário, que possui características específicas que podem ser melhor compreendidas numa perspectiva analítico institucional.
\end{abstract}

Palavras-chave: socialização profissional, professores universitários, professores iniciantes

\footnotetext{
${ }^{1}$ Professor Adjunto I da Faculdade Interdisciplinar em Humanidades da UFVJM, Doutor em Psicologia pela PUC-Minas. Apoio CAPES.

${ }^{2}$ Professora Adjunto III da Faculdade de Psicologia da PUC-Minas, Doutora em Psicologia Clínica pela PUC/SP
} 


\begin{abstract}
Considering the expansion occurred in the federal public university during the 2010s, this paper aims to analyze factors associated to the process of professional socialization concerning a group of professors who teach in five faculties and institutes from a university in the countryside of Minas Gerais, Brazil. Among them, ten inexperienced and recently hired professors were interviewed; only two ancient professors have been listened. Beyond that, between 2014 and 2015 we made field research and collected data that would be further analyzed. Through this analysis we found some factors associated to the professional socialization, here they are: the entry in the university, the contract as a public agent, the home moving and resulting way of life, their relation with their families and finally the shifting form a PhD student status to professor in the university. From that, we concluded that the professional socialization process we analyze could be understood as a moment of tension between the new comers power and the instituted power in the university, whose features might be better analyzed in a institutional perspective.
\end{abstract}

Keywords: professional socialization, university professors, beginner teachers

\title{
Introdução
}

Recentemente vivemos no Brasil um aumento da entrada de professores universitários. Entre os anos de 2000 e 2013, no contexto do Programa de Reestruturação e Expansão das Universidades Federais (REUNI), o quantitativo de vagas docentes em universidades federais dobrou, saltando de 50.165 vagas para 101.376 vagas. Concomitantemente, não há programas sistematizados de recepção, acolhimento e desenvolvimento na carreira destes profissionais (BONADIMAN, 2016).

De acordo com Dubar (2005), o processo de socialização profissional pode ser compreendido com as construções identitárias relacionadas às transações objetivas e subjetivas que ocorrem de dentro e de fora do ambiente de trabalho. No caso dos professores universitários iniciantes, o processo de socialização pode estar relacionado à construção de uma profissionalidade a partir dos descritores apontados por Roldão (2005), a saber: o poder, um saber próprio, a clareza da função social desempenhada e o sentido da comunidade profissional.

Nessa direção, o professor universitário iniciante pode ser identificado como um profissional em construção, com características específicas da sua história de vida e da sua formação universitária, dentre as quais se destacam a transição de estudante de doutorado a professor universitário e a presença ou ausência de dispositivos do estabelecimento 
universitário que favoreçam o desenvolvimento na carreira nos três primeiros anos de exercício profissional (BOZU, 2009; PINTO, 2010).

De modo exploratório, no desenvolvimento de uma parcela de pesquisa de doutoramento, objetivou-se compreender os fatores que interferem no processo de socialização profissional de professores universitários iniciantes a partir da perspectiva da Análise Institucional de Lourau (1995).

\section{O processo de socialização profissional na perspectiva analítico-institucional}

Para Dubar (2005), a socialização seria a maneira pela qual os indivíduos aprendem e se inserem numa cultura, seja profissional, seja no ambiente familiar, resultando na construção de uma identidade profissional forjada nas interações dos sujeitos com a cultura de trabalho. Desse modo, a socialização profissional ocorre quando os saberes para o exercício profissional são minimamente aprendidos e incorporados às práticas cotidianas dos sujeitos em relação aos estabelecimentos que os empregam e os colocam sob contingências específicas de produção no trabalho.

Tabela 1: Os quatro processos identitários típicos

\begin{tabular}{cccc}
\hline $\begin{array}{c}\text { Identidade } \\
\text { para si }\end{array}$ & $\begin{array}{c}\text { Identidade } \\
\text { para o outro }\end{array}$ & Reconhecimento & Não reconhecimento \\
\hline \multirow{2}{*}{ Transação } & \multirow{2}{*}{ Continuidade } & PROMOÇÃO (interna) & BLOQUEIO (interno) \\
\cline { 2 - 4 } subjetiva & \multirow{2}{*}{ Ruptura } & Recapacitação (externa) & Exclusão (externa) \\
& & Identidade de rede & Identidade de fora do \\
& & & trabalho \\
\hline
\end{tabular}

Fonte: Dubar (2005)

Na tabela apresentada, Dubar (2005) sintetizou as duas formas identitárias básicas que são construídas através de transações subjetivas e objetivas, por meio dos processos de continuidade e ruptura. As formas identitárias construídas por Dubar (2005) são móveis e fluidas, podendo obter alguma estabilidade no tempo de acordo com a profissão exercida e o emprego fornecido. 
Além das questões interacionais das transações subjetivas e objetivas propostas por Dubar (2005), a compreensão do processo de socialização profissional pode ser enriquecido se analisado sob a ótica das várias instituições que permeiam um mesmo estabelecimento. Uma mesma empresa ou organização, na ótica de Lourau $(1993,1995)$, será atravessada por diversas instituições. Para compreender a socialização na perspectiva analítico-institucional, faz-se necessário definir alguns conceitos de Lourau (1995) e da corrente teórica da qual ele faz parte.

De acordo com Romagnoli (2014), Lourau situa-se no movimento institucionalista francês sendo fundador, junto com Georges Lapassade, da Análise Institucional. O movimento institucionalista buscou quebrar com paradigmas das ciências naturais e das ciências humanas, através de níveis de análise não experimentados por outras teorias. Também possui como fundamento a participação ativa dos pesquisadores nas realidades pesquisadas, com o propósito de transformar as práticas ali desenvolvidas. Grande parte do que se conhece como pesquisa-intervenção pode ter, no movimento institucionalista, um dos seus fundamentos (ROMAGNOLI, 2014).

Para Lourau (1995), a Análise Institucional foi fundada no entrecruzamento de diferentes perspectivas do conhecimento, principalmente nos temas e problemas de pesquisa que naturalizaram os fatos sociais. Uma de suas primeiras e principais definições, desenvolvida em sua Tese de Estado ${ }^{3}$ defendida em 1969 e publicada em 1970, é o conceito de instituição. Lourau (1995) faz uma extensa revisão do emprego da palavra instituição na filosofia do direito, sociologia, na antropologia e no marxismo, apontando suas lacunas e limites de utilização, favorecendo a criação de uma outra compreensão. Para o autor, a instituição pode ser compreendida como uma norma geral, que apresenta momentos de estabilidades e rupturas através dos seus processos de tensão entre o instituinte e o instituído, tendo como uma das suas principais características o atravessamento de instâncias. Nesse sentido, a instituição possui um movimento, possibilidades de transformação.

De acordo com Lourau (2004a, p. 71),

Primeiro, as instituições são normas. Mas elas incluem também como os indivíduos concordam, ou não, em participar dessas mesmas normas. As relações sociais reais, bem como as normas sociais, fazem parte do conceito de instituição. Seu conteúdo é formado pela articulação entre a ação histórica

\footnotetext{
${ }^{3}$ A Tese de Estado era pré-requisito para o exercício da docência universitária na França até o ano de 1984 (GIRAUD, 1996).
} 
de indivíduos, grupos, coletividades, por um lado, e as normas sociais já existentes, por outro.

Segundo, a instituição não é um nível de organização social (regras, leis) que atua a partir do exterior para regular a vida dos grupos ou as condutas dos indivíduos; atravessa todos os conjuntos humanos e faz parte da estrutura simbólica do grupo, do indivíduo.

Logo, pertence a todos os níveis de análise: no nível individual, no da organização (hospital, escola, sindicato), no grupo informal bem como no formal, encontramos a dimensão da instituição.

Tratando-se de um conceito dinâmico, que não possui uma única instância de análise, a instituição é abordada como um objeto móvel, sendo uma das suas principais características o atravessamento, que foi definido por Baremblitt (2012, p. 152) como "a rede social do instituído-organizado-estabelecido, cuja função prevalente é a reprodução do sistema”. O atravessamento garante que aspectos semelhantes em alguns níveis da instituição estejam presentes em outros níveis. Por outro lado, a instituição também é composta por forças instituintes, que fazer surgir situações inéditas, elementos novos no cotidiano institucional com a predominância da produção, motor de câmbio do sistema social, essa outra característica se se refere à transversalidade, que corresponde à "interpenetração, entrelaçamento, no rizoma (...) que é imanente à rede social, das forças produtivo-desejanteinstituintes-organizantes" (BAREMBLITT, 2012, p.195). Essas forças estão presentes na instituição, e sustentam o processo de institucionalização, processo de conexões, mesclas e interferências de forças contraditórias, que trilham caminhos que ora levam as mesmas a institucionalizar-se, e a reproduzir-se ora conduzem à mudanças e inovações.

Na condição de instituição, a universidade passa pelo processo de institucionalização, por meio da construção do campo de forças entre instituído e instituinte. Para Lourau (2004b), o instituinte pode ser compreendido como a contestação, e a capacidade de inovação e o instituído pode ser compreendida como as formas já estabelecidas. O campo de forças entre instituído e instituinte, dessa maneira, foi utilizado para a compreensão das dinâmicas da socialização profissional dos professores universitários iniciantes, uma vez que este se dá em cenários institucionais, entre forças que tentam reproduzir e forças que buscam a invenção.

\section{Metodologia}

Trata-se de pesquisa qualitativa que se orientou pela construção de analisadores. A análise institucional propõe-se como uma forma de produção de conhecimento na qual teoria e método são indissociáveis. Por essa razão que o conceito de instituição proposto por Lourau 
(1995) está atrelado ao conceito de analisador, que pode ser compreendido como um mecanismo provocado ou natural que faz com que a instituição se torne acessível. Os analisadores podem ser entendidos como efeitos ou fenômenos que emergem como resultado de um campo de forças contraditório e incoerente, porta-vozes insistentes da turbulenta gama de conflitos que se encontram em assídua oposição ao harmônico e ao estático acalentado pela instituição. Compreender a socialização profissional, nessa perspectiva, significa desvendar, construir e analisar os atravessamentos e conflitos que ocorrem durante seu processo, de modo natural ou provocado.

Nesta direção, os analisadores foram construídos a partir de entrevistas e observações de campo realizadas nos anos de 2014 e 2015 no estabelecimento universitário em estudo. O estabelecimento era multicampi, possuía mais de quatrocentos professores efetivos no campus sede e oferecia cursos de graduação e pós graduação em todas as áreas do conhecimento. $\mathrm{O}$ campus sede, situado numa cidade com pouco mais de cinquenta mil habitantes, foi escolhido em função do quantitativo de docentes e das possibilidades do pesquisador.

A tabela a seguir descreve os professores entrevistados: pseudônimo, idade, titulação, tempo de exercício no estabelecimento universitário, área do conhecimento de pertencimento e tempo de entrevista. A área de conhecimento está atrelada à faculdade na qual o docente exerce suas funções e a formação doutoral.

Tabela 2: Dados dos professores universitários entrevistados

\begin{tabular}{|c|c|c|c|c|c|}
\hline Pseudônimo & Idade & Titulação & $\begin{array}{c}\text { Tempo de } \\
\text { exercício } \\
\text { (anos) }\end{array}$ & Área & $\begin{array}{c}\text { Duração } \\
\text { da } \\
\text { entrevista }\end{array}$ \\
\hline Alda & 32 & Doutora & 2 & Ciências Humanas & $01 \mathrm{~h} 06 \mathrm{~m}$ \\
\hline Margarete & 33 & Doutora & 2 & Ciências Humanas & $01 \mathrm{~h} 25 \mathrm{~m}$ \\
\hline Paulinho & 33 & Doutor & 3 & $\begin{array}{c}\text { Ciências sociais } \\
\text { aplicadas }\end{array}$ & $00 \mathrm{~h} 43 \mathrm{~m}$ \\
\hline Marilza & 29 & Doutora & 2 & Engenharia & $00 \mathrm{~h} 42 \mathrm{~m}$ \\
\hline Ramon & 32 & Doutor & 1 & Ciências Biológicas & $00 \mathrm{~h} 48 \mathrm{~m}$ \\
\hline Maria José & 32 & Doutora & 2 & $\begin{array}{c}\text { Linguística, letras e } \\
\text { artes }\end{array}$ & $01 \mathrm{~h} 08 \mathrm{~m}$ \\
\hline
\end{tabular}




$\begin{array}{cccccc}\text { Simone } & 37 & \text { Doutora } & 3 & \text { Ciências Agrárias } & 00 \mathrm{~h} 35 \mathrm{~m} \\ \text { Henrique } & 30 & \text { Mestre } & 2 & \text { Engenharias } & 00 \mathrm{~h} 45 \mathrm{~m} \\ \text { Carlos } & 28 & \text { Mestre } & 1 & \text { Engenharias } & 00 \mathrm{~h} 41 \mathrm{~m} \\ \text { Renato } & 49 & \text { Doutor } & 23 & \text { Ciências Biológicas } & 01 \mathrm{~h} 40 \mathrm{~m} \\ \text { Galvão } & 45 & \text { Doutor } & 7 & \text { Ciências sociais } & \\ \text { Penha } & 34 & \text { Mestre } & 1 & \text { Ciências Humanas } & 00 \mathrm{~h} 43 \mathrm{~m}\end{array}$

Fonte: elaborado pelo autor

As observações foram realizadas durante o período de exercício profissional do pesquisador em reuniões colegiadas, momentos de lazer e alimentação e nos corredores das unidades acadêmicas. Os analisadores foram interpretados a partir do conceito de instituição e de socialização profissional no contexto das atividades cotidianas de trabalho.

\section{Resultados}

Quando o professor universitário inicia suas atividades profissionais, sendo este professor um elemento instituinte naquele novo estabelecimento, é possível que ele mobilize uma série de estratégias de adaptação à nova realidade. Das inúmeras práticas previstas na profissão de professor universitário, os primeiros comportamentos, encontros com os colegas, formas de se relacionar com a administração do estabelecimento, dentre outras, são situações que revelam, no enredo cotidiano, as formas que os elementos instituintes se confrontam com o instituído. Não por menos, são situações repletas de confrontação, de negação do que já existe, nas quais o instituído é posto à prova em todo momento.

\section{A posse e os primeiros dias}

Na pesquisa foi comum encontrar professores que, ao chegarem no novo trabalho, não possuíam orientação adequada do estabelecimento de ensino. Mesmo após a posse, a orientação era procurar a faculdade ou o departamento onde seriam lotados. O campus, no entanto, não contava com placas indicativas, cabendo aos poucos transeuntes uma informação incompleta de onde ficava o local de trabalho. Após andar mais de 600 quilômetros para tomar posse, uma professora em cuja recepção o pesquisador contribuiu, experimentou certa 
insegurança ao não saber para onde ir e passar por mais de quatro edificações até "acertar" qual seria seu local de trabalho. Após essa caminhada, o professor Ramon relata como foi recebido:

$\mathrm{Eu}$ fui bem acolhido aqui no sentido de que eles me mostraram o departamento, me ensinaram como o departamento funciona, a parte do SIGA (Sistema Integrado de Gestão Acadêmica), me mostraram aonde que eu tinha que ir se eu tivesse alguma dúvida sobre tal assunto, onde eu tinha que resolver os assuntos. Sempre que eu tinha uma dúvida eu ia na sala deles, eles paravam o que estavam fazendo para me responder, para me ajudar. Isso foi ótimo. (Ramon)

Das recepções analisadas nas entrevistas, a do professor Ramon foi a que contou com maior apoio dos colegas. De modo semelhante, o professor Carlos também considera que foi bem recebido pelos colegas:

Você não tem o SIAPE. Você não existe, praticamente, então você não consegue fazer nada. Um professor me deu alguns pinceis, o outro me deu um pacote de folhas, caso eu precisasse imprimir, disponibilizou a impressora, que alguns já têm aqui. Isso tudo amenizou o fato de eu chegar no meio do semestre. Eles me mostraram exatamente qual sala que eu ia dar aula, me apresentaram para o pessoal que você tem que pegar a chave e o controle do projetor. Eu diria que foi muito tranquila a minha chegada aqui. (Carlos)

Os relatos dos professores Carlos e Ramon podem ser uma exceção, quando verificamos o relato da professora Simone:

Não, ninguém explica nada. Eu cheguei, tomei posse. Foi até o vice-reitor que fez a apresentação. Foi bem agradável. [...] Pelo menos já tinha uma sala. Antes eles não tinham, era tudo dividido, o pessoal não tinha muita estrutura. Eu já cheguei com a minha sala, com as minhas coisas. Eu cheguei aqui e já tinha um computador para mim, chegou já um computador, a impressora. Chegou tudo muito rápido. Então, assim, eu não tive grandes problemas com isso, de parte física. A parte de estrutura dos prédios de aula também foi boa, não tive problema com datashow, com nada. Mas, assim, apresentar a universidade quem fez foi os próprios professores daqui. $\mathrm{O}$ chefe de departamento me pegou e levou para mostrar os prédios mais ou menos, o que é que era cada coisa. Por parte da universidade mesmo a gente não tem esse tipo de apresentação não. E entrar em sala de aula é assim, você chega lá no prédio, lá tem uma salinha que chama "áudio e vídeo", você vai lá, pega o seu datashow, e pronto. (Professora Simone).

Ou, ainda, quando verificamos o relato da professora Alda: 
O dia que eu tomei posse eu fui recebida pelo vice-reitor. [...] E aí eu descobri sozinha aonde que era o prédio de aula, onde que eu ia dar aula. Falaram que a gente tinha sala. Tinham muitos gabinetes vazios, foi uma festa, porque a gente ficava entrando de gabinete em gabinete e: "Ah, esse é meu gabinete!". Mas isso a gente fez tudo sozinha, a gente, assim, os professores que estavam chegando. A gente olhou gabinete, escolhi meu gabinete. Trouxe já algumas coisas. Não, mentira, porque eu não tinha ainda coisas para trazer. (risos). Eu tinha só meia dúzia de roupa. Estava naquela, procurando casa, onde que eu ia morar, o que ia fazer, comprar carro, pegar ônibus, pegar carona. (Professora Alda)

Os relatos dos três professores exemplificam o processo de entrada no estabelecimento universitário e da sua recepção. Com exceções, há relatos de conteúdo diferente, como o caso dos professores que ingressaram e já foram substitutos no estabelecimento ou o caso dos professores que possuíam algum familiar que trabalhava no local. As narrativas mostram que as inserções na universidade foram realizadas de forma pessoal, não tendo um procedimento, uma norma institucional nesses casos, o que favorece uma lida pessoal e individual com o momento, sem um aporte da universidade, denotando uma contradição em uma instituição pública, a qual provavelmente o professor permanecerá até se aposentar.

A solidão inicial da posse, suprida pelo acolhimento dos colegas de curso, demonstra o cenário solitário de entrada na Profissão de Magistério do Ensino Superior, conforme aponta Roldão (2005). Os relatos triangulam-se com as observações: da manutenção da fachada inicial ao atendimento de algumas necessidades básicas, a socialização profissional dos professores iniciantes possui, ainda, mais alguns percalços. Trata-se de chegar numa cidade diferente e se instalar, demandando esforços das mais variadas ordens.

\section{A adaptação a nova cidade}

Todos os professores iniciantes entrevistados não são originários da cidade onde se situa o campus, sequer da macrorregião. A entrada no novo trabalho requer, ainda, uma adaptação à cidade que envolve o aluguel ou a compra de uma casa, as atividades de lazer durante a semana ou nos finais de semana, o acesso a serviços básicos, os laços com as pessoas da cidade, saber qual a melhor padaria para comprar pão, entre outros. Tratando-se de consenso entre os entrevistados, pontos positivos e negativos podem ser elencados nesse processo de adaptação na cidade.

Perguntei ao professor Ramon se ele desejava se mudar. Disse-me que seria algo natural, pois "os professores sempre comentam: "Esta cidade... Nossa, até se acostumar!". O 
contexto que o professor circunscreve para uma possível alteração do local de trabalho possui estreita relação com o que a cidade oferece ou deixa de oferecer, de supermercados a serviços.

A professora Margarete, por sua vez, destaca que

Talvez a minha maior dificuldade de adaptação [...] e que agora eu estou sentindo muito mais do que antes, no início, é essa questão do não ter muitas coisas. Desde os meus três anos de idade eu morei numa cidade capital, que tinha tudo em volta. [...] Aqui eu tenho essa dificuldade de coisas que para mim em Porto Alegre eram básicas, por exemplo, ir ao shopping ver um filme no cinema. Aqui não tem, e aí fica aquela coisa do fim de semana vago. (Margarete)

De modo semelhante, segue o relato do professor Henrique:

Mas a impressão que eu tinha [...] era de ser uma cidade bem mais moderna, desenvolvida. Sim, tem a parte histórica, mas que ao redor da parte histórica tivesse um comércio mais desenvolvido. Chegando aqui eu percebi que não era bem assim. Foi um pouco frustrante mesmo saber que a cidade em si não oferece, por exemplo, um comércio mais variado, é bastante limitado. (Henrique)

A cidade que abriga o campus é tipicamente de interior, cidade polo de outras pequenas cidades, muito diferente das capitais ou regiões de origem dos professores iniciantes. Adaptar-se às novas contingências culturais e de opções de consumo passa a caracterizar o cotidiano como algo que dificulta a socialização profissional dos iniciantes. Morar em uma pequena cidade requer repertórios específicos, mas também possui contrapontos da maior grandeza, que podem equacionar o que, à primeira vista, foi tomado como um problema. Segue a professora Margarete:

No início, eu me dei conta de que, por ser de fora, alguns serviços da cidade eram cobrados a mais. Por exemplo, um táxi era mais caro por causa do meu sotaque. Eles têm uma ideia das pessoas do sul, e a ideia das pessoas do sul é que as pessoas são todas civilizadas, brancas e, de uma forma, todas ricas, e aí tu chega [sic] num lugar que não conhece, o taxista vai cobrar mais porque tu fala [sic] diferente. Inclusive, eles falam isso para a gente: "Ah, porque lá no sul todo mundo é rico, não tem favela". Umas coisas que são inimagináveis. E outras coisas também, mas que são relativas não somente a ser de outro lugar, mas por ser professor nessa cidade, que também é outro tipo de adaptação. As pessoas nos veem de forma diferente. Não é como se eu fosse professora, por exemplo, em Porto Alegre, que têm milhares de professores naquela cidade, então é uma coisa normal, as pessoas não vão me reconhecer na rua por ter esse cargo. Mas (aqui) tu é [sic] a professora, a professora que mora na rua tal. 
A "professora da rua tal" é típico de uma cidade de interior, uma tipicidade pouco vivenciada por aqueles que possuem origem nos centros urbanos. A colocação social, o status e certo reconhecimento são comuns. Pode-se estar diante de uma característica típica de universidades do interior.

As dificuldades para encontrar uma casa também estão presentes em muitos relatos dos professores iniciantes. Atribui-se ao crescimento da universidade a insuficiência de imóveis para venda e aluguel, sendo muito comum a mudança frequente de casa nos primeiros anos de exercício e queixas sobre os imóveis nas mesas de café e reuniões de professores. É o caso de professores que observei em uma das unidades acadêmicas. Quando algum professor relatava que havia conseguido uma boa casa ou apartamento, outros se apressavam para anotar contatos e pedir referências. Aqueles que encontraram uma casa rapidamente, aceitaram um aluguel elevado para os padrões da cidade e, muitas vezes, sem garagem. Pela questão topográfica da cidade e sua história, uma garagem é sinônimo de algum luxo.

Nesse processo, há aqueles que criaram, ainda, uma relação com a cidade insuportável. É comum em alguns professores as idas frequentes a centros urbanos próximos $(250 \mathrm{Km})$ apenas para "ver um movimento". É como relata o professor Paulinho, que viajava frequentemente: "Eu acredito que o professor é muito solitário aqui, a nossa atividade é muito solitária. Não é fácil... Eu ia ao mercado, e é terrível quando você está sozinho e todo mundo está conversando nas outras mesas".

Dos relatos de "choque" na adaptação à cidade, apenas o professor Carlos relata uma adaptação favorável à cidade, quando diz: "estou adorando esse lugar, talvez porque está perto de Belo Horizonte". Talvez a boa adaptação, além da resiliência, pode ser explicada pelo fato do professor ter nascido e vivido em cidades do interior.

De um contato inicial cotidiano, das primeiras impressões do estabelecimento e do contato com a cidade, a entrada na profissão de professor universitário apresentou, ainda, a influência da transição de estudante universitário a professor universitário e a influência da família.

\section{Da transição de estudante de doutorado a professor universitário}

Após a defesa das teses de doutoramento e recém-ingressados no serviço público, os professores iniciantes adotaram modelos de conduta semelhantes aos modelos vivenciados 
enquanto estudantes ou, pelo menos, faziam referências emotivamente consistentes ao se referirem aos professores da pós-graduação ou da Educação Básica. É o caso do professor Ramon:

Ele foi meu professor em 97, 98 e 99. Ele é ótimo. Ele é fantástico. Na época eu tinha uma ideia, eu gostava de dinossauro, eu queria ser paleontólogo e eu não sabia exatamente o que eu tinha que fazer para ser paleontólogo. Um belo dia caiu a ficha, eu falei: "Pode ser que... Será que é mesmo?". Eu adorava as aulas dele, achava aquilo fantástico. O professor foi, sem dúvida nenhuma, um dos meus cinco melhores professores até hoje. Mas ele não vai lembrar de mim não. [...] Ah! Aí eu tenho a minha lista dos professores. Tenho o Lucas, tem outro professor lá de Goiânia, que era o Siqueira, um professor fantástico também, os meus dois orientadores, o meu orientador de iniciação científica e de mestrado, o professor João e o professor Alexandre, que foi o meu orientador de doutorado, e o professor Passos, eles são os cinco professores melhores que eu tive e eu me espelho neles. Eu fico tentando lembrar como eles faziam. Tinha uma coisa que o Lucas fez, que ele conseguia fazer e que eu achava fantástica. Ele mantinha uma seriedade dentro de sala de aula fora de série, e ele não dava muita margem para a gente não prestar atenção. Ele exigia da gente o tempo inteiro. Era o único desses cinco que fazia isso, ele conseguia exigir da gente, o tempo inteiro exigindo mesmo, mas ele mantinha a cordialidade, ele não faltava com educação com a gente em momento algum. (Ramon)

O professor Ramon, além de pertencer a uma família de professores, sendo que sua esposa também é professora universitária, recebeu não apenas influência para seguir a carreira docente. É perceptível que os professores da pós-graduação e, de modo especial, um professor da educação básica, sirvam de modelo para a sua prática atual.

Na perspectiva da Análise Institucional, a modificação do estatuto de aluno para o estatuto de professor universitário pode ser lida como a manutenção de uma institucionalização ordinária. Em outras palavras, há uma temporalidade da instituição docência que permanece e emerge nos embates entre o instituído e o instituinte no início da carreira de Professor do Magistério Superior. Essa instituição possui tal força, que é perceptível, inclusive, na manutenção de um ideário pedagógico. O professor Ramon admira o professor Lucas pelos seus feitos pedagógicos, como manter uma turma sob exigência durante todo o tempo.

Além de servirem de modelos para o exercício da profissão, em alguns casos, as relações com os orientadores de doutorado permanecem mesmo após o término do doutorado ou do mestrado. É o caso da professora Margarete: 
Então, até hoje a gente tem contato. Ele ficou muito feliz quando ficou sabendo que eu passei aqui. Realmente são pessoas que eu tento me espelhar até para dar aula, por essas questões metodológicas mesmo de dar aula, que eu sei que é uma coisa que deu certo. Não quer dizer que eu imite eles, mas realmente são pessoas que ajudam muito até hoje na minha formação (Margarete)

Em direção semelhante, segue relato da professora Penha:

E na oportunidade do mestrado eu quis dar continuidade, entrar na docência no Ensino Superior, que foi uma coisa que me foi apresentada no Ensino Superior, uma coisa que me despertou interesse no Ensino Superior a partir das práticas de alguns professores que eu tive e que eu admirei bastante. $\mathrm{O}$ Antônio, que é seu conhecido também, por exemplo, é um desses professores. Ele também foi um dos professores que me deu muito apoio, muito direcionamento para continuar com os estudos, principalmente na carreira acadêmica. (Penha)

Nas observações realizadas durante a pesquisa, eram comuns as referências aos orientadores de doutorado, principalmente para aqueles que submetiam um primeiro projeto de pesquisa às agências de fomento ou que possuíam artigos pendentes de publicação. Nas duas situações, as relações de amor e ódio com substancial carga afetiva nas referências ao período doutoral eram visíveis, como momento doloroso da formação, muitas vezes evocados na submissão de um novo projeto de pesquisa e no ato de recorrer aos orientadores de doutorado.

A lembrança e a influência dos professores da própria formação na prática didática atual é fenômeno conhecido para a educação básica. No ensino superior, o tema foi abordado por Cunha (2009) quando se referiu à ausência de formação pedagógica dos professores do ensino superior, sendo a pedagogia colocada em segundo plano nas universidades.

Esse acesso direto ao campo subjetivo do professor Ramon ocorre no contexto da exposição de práticas pedagógicas utilizadas por ele que contêm, dentre outros elementos, uma visão de aluno, uma noção de ensino aprendizagem e uma noção de didática. Para o professor Ramon, o aluno precisa passar por uma série de ritos acadêmicos para ser considerado bom. Isso inclui provas, listas de exercícios e um código de postura, sendo o papel de tornar o que é difícil mais compreensível, de acordo com o modelo de professor que o próprio Ramon construiu em sua história. 
disciplinas que tem uma complexidade diferente, elas não são disciplinas simples. Aliás, são disciplinas que eu gosto de ministrar. Genética e Biologia Molecular, não, não é minha área, mas Evolução e Estatística eu gosto por causa dele, inclusive. Eu sou professor de Evolução aqui também. Ele conseguia transformar aqueles conceitos complexos, e são muito complexos mesmo, numa linguagem muito fácil. Eu ouvia e falava: "Meu Deus, era só isso? É tão simples assim?". Ele falava com uma tranquilidade, com uma naturalidade que eu consegui transformar isso em pouco tempo, coisas complexas, em coisa simples, fáceis de entender. É o mais importante para mim. Segundo é a forma que ele se portava com a gente em sala de aula também: extremamente educado, extremamente cordial, atendia a gente muito bem tanto em sala quanto fora de sala de aula, e a gente criava um vínculo com ele. Eu acho importante o aluno criar vínculo com o professor, primeiro porque depende de confiança, o aluno precisa confiar no professor. Se ele não confiar, tudo aquilo que a gente está passando se perde, o aluno vai olhar para a gente e falar: "Será que é verdade mesmo? Esse 'cara', não consigo acreditar nele", e (palavra incompreensível) essa comunicação. O professor tem que ser acessível, o professor tem que estar disponível para o aluno a maior parte do tempo. É para isso que a gente está aqui, afinal de contas. O Alexandre fazia isso muito bem. Então eu acho que essas são as duas características muito boas dele. Todos os cinco tinham isso.

Notavelmente, o professor Ramon possui uma noção de transposição didática muito clara, construída na sua formação não apenas na pós-graduação, mas aperfeiçoada e reforçada de acordo com o seu objeto de estudo e seu campo do conhecimento. O que faz com que o caso do Ramon seja específico também se refere ao fato dele vir de uma família de professores. Sua naturalidade para falar da docência e o seu modo de se referir aos alunos, aos conteúdos e às suas aprendizagens pode ter sua origem ali. O curioso é que, mesmo sendo bacharel e sem ter feito disciplinas pedagógicas na sua formação, suas práticas revelam uma cultura de área bem definida e delimitada. Se a sua prática não foi problematizada pelas disciplinas pedagógicas e se seus professores são sua inspiração, Ramon pode ser considerado um representante da sua área.

Não foi interesse imediato desta pesquisa a prática pedagógica dos professores universitários. Este tema emergiu de modo colateral, no contexto da análise da formação na pós-graduação cursada pelos professores iniciantes. Ainda assim, revelou um ideário pedagógico criado no contexto do campo de conhecimento. Se cada campo do conhecimento possui um objeto ou objetos preferenciais, há o compartilhamento de "truques do ramo", nem sempre problematizados, que indicam uma cultura acadêmica da área. Isso se inicia quando alunos das áreas da saúde, por exemplo, carregam um compêndio de qualquer natureza e fazem seus lanches na cantina com os jalecos do laboratório. Também aparece quando as 
rodas de ciências humanas se formam, com estilos e temas de discussão exponencialmente diferentes das outras áreas.

Nesse contexto, também há a criação de uma noção de professor e noção de aluno. Esses significados compartilhados, que podem ser chamados de cultura profissional, nascem de um campo epistêmico e são compartilhados no estabelecimento universitário. Trata-se, portanto, de mais uma instituição que atravessa a universidade, anterior a ela, e que se revela em seu cotidiano.

\section{Da relação com a família}

As dez entrevistas com professores iniciantes revelaram que a instituição família ocupa um lugar central na adaptação ao trabalho e de diferentes formas: para uns, a aceitação do cargo após o concurso está condicionada a questões familiares. O professor Ramon, por exemplo, com formação na área de Ciências Biológicas, fez suas escolhas em comum acordo com as pretensões da sua companheira. Quinzenalmente, ele viaja mais de mil quilômetros, por um dia inteiro, para passar o final de semana junto a ela. Reciprocamente e quinzenalmente, ela, que também é professora, viaja para encontrá-lo.

A professora Marilza, natural do Estado da Bahia, casada com um companheiro da região sul de Minas Gerais, considera de grande valia trabalhar na universidade porque a distância entre a casa dos seus pais e dos sogros ficou melhor distribuída. Nas palavras da professora Marilza:

Eu já vim para cá assim: estou indo e já estou indo para ficar. Até porque o seguinte, a localização daqui para mim é estratégica. A minha família está na Bahia, a $700 \mathrm{~km}$ daqui, e a família do meu marido está a $500 \mathrm{~km}$, e a gente está no meio. Aqui foi para mim a solução do problema de distância da família, porque eu ia estar um pouco mais perto. Quando eu estava no sul de Minas eu estava a $1200 \mathrm{~km}$ da minha família, hoje eu estou a 700.

Nos dois casos, pode-se sugerir que a família ocupa um lugar de centralidade que antecede e orienta a escolha do local de trabalho. Existe a conveniência e o sonho do concurso público, de tempos em tempos mais concorrido para todas as áreas, porém, a instituição família, por vezes, coloca-se como um atravessamento profissional da maior grandeza. Isso pode ser observado, por exemplo, quando a professora Margarete foi questionada sobre a possibilidade de modificação do local de trabalho. Margarete é enfática em dizer que uma 
nova escolha só ocorreria em função da distância da casa dos seus pais, uma vez que estão mais idosos e precisariam, de alguma forma, do seu auxílio.

A tabela abaixo sintetiza as formas em que a instituição família emergiu. Ressalta-se que a entrevista semiestruturada se deteve no questionamento sobre como cada professor chegou ao local de trabalho e como se adaptou à universidade e à cidade. Ou seja, a questão familiar foi colocada pelos próprios entrevistados como essencial, uma vez que nenhuma pergunta foi efetuada nessa direção.

Tabela 3: A instituição "família"

\begin{tabular}{|c|c|}
\hline Pseudônimo & Falas significativas \\
\hline Alda & Não houve \\
\hline Margarete & $\begin{array}{l}\text { É uma coisa que eu não posso simplesmente largar, esquecer deles lá, é uma } \\
\text { coisa que realmente eu tenho que pensar. }\end{array}$ \\
\hline Paulinho & $\begin{array}{l}\text { No meu caso, eu sou solteiro. Se tivesse a família seria um belo contraponto. } \\
\text { Embora eu não possa reclamar porque quando meus pais veem para cá eles } \\
\text { ficam um bom tempo. }\end{array}$ \\
\hline Marilza & $\begin{array}{l}\text { Foi o que facilitou a minha permanência aqui. Acho que acaba facilitando } \\
\text { quando você vem com a família (...) Já tiveram três professoras aqui que } \\
\text { acabaram não ficando porque o marido trabalhava em outro lugar. }\end{array}$ \\
\hline Ramon & $\begin{array}{l}\text { Sentir falta da esposa é difícil, então a gente encontra nos finais de semana. } \\
\text { Essa parte que é a mais complicada. }\end{array}$ \\
\hline Maria José & $\begin{array}{l}\text { Eu iria para qualquer lugar, mas quando falou que seria aqui, que não está } \\
\text { tão longe da casa da minha mãe, que é Minas, por mais que seja um } \\
\text { ambiente diferente, eu me sinto mais em casa aqui. }\end{array}$ \\
\hline Simone & Depois que a minha filha nasceu nunca mais eu fiquei sozinha. \\
\hline Henrique & $\begin{array}{l}\text { Minha mãe, meu irmão foram para Goiânia, então eu vir para Minas Gerais } \\
\text { acabou sendo até uma questão geográfica mais favorável. }\end{array}$ \\
\hline Carlos & $\begin{array}{l}\text { Quase todo final de semana eu vou visitar meus pais no Campo das vertentes } \\
\text { que, também não está longe, está uns } 500 \mathrm{~km} \text {. }\end{array}$ \\
\hline Penha & $\begin{array}{l}\text { Uma casa própria que eu tinha na minha cidade, uma proximidade com a } \\
\text { minha família, então aquilo para mim já era definitivo. Tirar isso que para }\end{array}$ \\
\hline
\end{tabular}


mim já estava posto é um pouco difícil até hoje

Romagnoli (2007) teceu relações entre a Análise Institucional e a instituição família que vão ao encontro das problematizações desta pesquisa. Ao definir a família nuclear como instituição, com especificidades históricas, a autora aponta que as diversas transformações do mundo contemporâneo, seja pela introdução das novas tecnologias, seja pela fluidez dos relacionamentos, fizeram com que o modelo de família nuclear fosse uma opção de segurança frente ao caos introduzido por diferentes materiais instituídos na contemporaneidade. Para Romagnoli (2007, p.107), "nos dias de hoje, a família nuclear, composta pelo casal unido em matrimônio e os filhos nascidos desta união e vinculada a uma concepção de mundo moderno, é utilizada como sinônimo de solidez e de adaptação às circunstâncias de nosso tempo". Mesmo em mutação, a família ainda é uma referência para a maioria de nós e para os professores entrevistados.

Para aprofundar a questão, relata-se uma cena que o pesquisador presenciou. Numa reunião de colegiado de curso, havia um pedido de análise de redistribuição de servidor público via transferência: um docente de outra região do país pleiteava vaga sob argumentos técnicos e pessoais. Pedido, currículo e memorial estavam sob análise. No que tange aos argumentos técnicos, o currículo preenchia todos os requisitos para aceitação da transferência. No entanto, reforça-se que os argumentos afetivos foram cruciais para a admissibilidade do pedido. A razão pessoal da servidora possuía relação com a doença de um dos membros de sua família que morava em Minas Gerais.

O pesquisador conheceu o servidor no seu primeiro mês de exercício. Antes de dialogar e colocar em prática os rituais acadêmicos, tais como "onde você fez seu doutorado?" ou “do que você pesquisa?", perguntou: "seu parente está melhor?”.

Retornando ao analisador "família" no processo de socialização, observa-se que a vida profissional, numa instituição de caráter de direito público, possui como atravessamento principal uma instituição do domínio da vida privada. Em outras palavras, a vida privada pode preceder o trabalho no domínio público, sendo a aceitação das diretrizes da vida familiar uma característica do processo de socialização.

\section{Considerações finais}


Compreender os analisadores do processo de socialização profissional dos professores iniciantes foi o objetivo principal desta pesquisa, que apontaram para a entrada inicial na instituição desde a posse, a transição de estudante a professor universitário e o papel da família no processo de socialização. Neste jogo de forças institucionais, percebe-se que os iniciantes podem ser compreendidos como uma força instituinte frente ao estabelecimento, que possui práticas instituídas - dentre elas a ausência de uma recepção adequada.

A este respeito, Muradás Lopes e Mendoza (2010) salientam a necessidade de políticas do estabelecimento que atendam à recepção e desenvolvimento profissional dos professores iniciantes. Como se verificou nos relatos da maioria dos professores iniciantes desta pesquisa, os relatos de práticas instituídas de recepção foram inexistentes.

Partindo-se do desafio de estudar professores universitários, salienta-se, por fim, que este estudo possui limitações evidentes, que pretendem ser problematizadas em pesquisas futuras, quais sejam: as relações de poder na universidade, uma descrição completa dos locais de trabalho e a comparação entre as áreas do conhecimento e como se dá a socialização em cada uma delas.

\section{Referências Bibliográficas}

BAREMBLITT, G. F. Compêndio de Análise Institucional e Outras Correntes: Teoria e Prática. 6. ed. Belo Horizonte: Editora FGB/ IFG, 2012.

BONADIMAN, H. L. Socialização profissional de professores universitários iniciantes. 2016. 195f. Tese (Doutorado em Psicologia)- Pontifícia Universidade Católica de Minas Gerais, Belo Horizonte, 2016.

BOZU, Z. El professorado universitário novel y su processo de inducción professional. Magis, Revista Internacional de Investigación em Educación. Bogotá, Colômbia. Vol. 1, N. 2, p. 317-328, jan.-jun., 2009.

CUNHA, M. I. O lugar da formação do professor universitário: o espaço da pós-graduação em educação em questão. Revista Diálogo Educacional, Curitiba, v.9, n.26, p. 81-90, jan.abr./2009.

DUBAR, C. A socialização: construção das identidades sociais e profissionais. São Paulo: Martins Fontes, 2005.

LOURAU, R. Análise Institucional e Práticas de Pesquisa. Rio de Janeiro: NAPE/UERJ, 1993. 
LOURAU, R. Objeto e método da análise institucional. In: ALTOÉ, Sônia (Ed.). René Lourau: Analista institucional em tempo integral (pp. 66-87). São Paulo, SP: HUCITEC, 2004a.

LOURAU, R. O instituinte contra o instituído. In: ALTOÉ, Sônia. (Ed.), René Lourau: Analista institucional em tempo integral (pp. 47-65). São Paulo, SP: HUCITEC, 2004b.

LOURAU, R. A análise institucional. 2. ed .Petrópolis, RJ, Vozes, 1995.

MURADÁS LÓPEZ, M.; MENDOZA, P. (2010). ¿Se pueden socializar profesores universitarios en buenas prácticas docentes? El caso del proyecto Visibilidad. Education Policy Analysis Archives/Archivos Analíticos de Políticas Educativas, s/d, 1-25.

PINTO, M. G. G. O lugar das práticas pedagógicas e dos saberes docentes na formação de professores. Acta Scientiarum. Education. Maringá, v. 32, n. 1, p. 111-117, 2010.

ROLDÃO, M. C. N. Profissionalidade docente em análise - especificidades dos ensinos superior e não superior. Nuances: estudos sobre educação. Presidente Prudente - ano XI, v. 12, n. 13 , jan.-dez./2005.

ROMAGNOLI, R. C. O conceito de implicação e a pesquisa-intervenção institucionalista. Psicologia e Sociedade, Belo Horizonte, v. 26, n.1, 2014.

ROMAGNOLI, R. C. O pensamento institucionalista e a transformação da família. In: CEVERNY, Ceneide (org.). Família, movimento e transformação. São Paulo: Casa do Psicólogo, 2007, p. 97-119 